\title{
Balance produción-consumo de alimentos na Galiza: aproximación dende a soberanía alimentar e a comercialización local
}

\author{
Galician production/consumption food balance: an approximation from \\ alimentary soverignty and local commerce point of view \\ EMILIO V. CARRAL VILARIÑO \\ Escola Politécnica Superior de Enxañería. Univ. de Santiago de Compostela \\ ORCID: 0000-0002-7909-047X \\ emilio.carral@usc.es. \\ XOÁN CARLOS CARREIRA PÉREZ \\ xoancarlos.carreira@gmail.com
}

\section{RESUMO}

Dende a perspectiva da soberanía alimentar analízanse os dados de produción-consumo na Galiza tomando como referencia as estatísticas oficiais do Ministerio de Agricultura e Pesca do estado español. Ademais realízase unha análise sectorial por bacías alimentares-comarcas naturais e grandes aglomeracións urbanas. Obtense un balance global positivo no producido na Galiza, con déficits parciais nos cereais gran e froiteiras. Os habitantes potencialmente auto-abastecidos/as dentro da súa propia comarca (comercialización local) supera o 50\% no caso dos cultivos forraxeiros, prados e pasteiros e tamén no viñedo. Máis do $60 \%$ en patacas e $70 \%$ se incluímos cultivos hortícolas e as leguminosas gran.

Palabras chave: Produción, consumo, bacía alimentar, Galiza.

\section{SUMMARY}

Under food production-consumption sovereign in relationship with Galiza, data base from Minister of Agriculture and Fisheries (Spanish national government) was analysed. Foodshed base on natural counties and urban agglomeration were defined to. As final results, Galiza are under a positive balance production/consumption for it food self-production, with deficit balance for fruit and graincereal. From the food sovereign and market proximity point of view more than $50 \%$ foodshed population are self-sufficient in relationship with forage cultivation and wine production, about $60 \%$ for potatoes and $70 \%$ when horticultural/grain leguminous production are included.

Keywords: Food production, consumption, foodshed, Galiza. 


\section{INTRODUCIÓN}

A procura do equilibrio entre produción de alimentos, seguranza alimentar, soberanía alimentar e a preservación do capital natural e sociocultural asociados a dito feito produtivo, mais tamén ao de consumo e de comercialización, é un dos desafíos máis importantes do século XXI (UN-2015). Na actualidade a relación entre capital socio-ecolóxico e capital financeiro (industrialización, infraestruturas, comercialización de escala) leva normalmente a situacións onde as taxas de troca son negativas para os primeiros factores, mais non sempre é así, xa que son numerosas as experiencias produtivas que corresponden a escenarios equilibrados entre capital socio-ecolóxico e económico-produtivo, o chamado modelo "win-win" (Hanspach et alii, 2017). Neste senso, na presentación do informe da FAO titulado "Agricultura mundial: cara os anos 2015/2030", Jacques Diouf (daquela Director Xeral), chama a atención sobre o feito de que en numerosos estudios que teñen avaliado os efectos dun comercio máis libre chégase á conclusión de " que uns obstáculos mais baixos ao comercio poden non ser suficientes para proporcionar un beneficio aos países en desenvolvemento" (Diouf, J., 2002, páx. iv) .

Xa no 2007, o relator especial da ONU sobre o dereito á alimentación, Jean Ziegler, afirmou "Todas as causas da fame son debidas ao home, é un problema de acceso, non de superpoboación ou subprodución, e pode ser modificado por decisión humana” (Ziegler, J., UN News Centre, 2007). Actualmente máis de 800 millóns de persoas pasan fame no noso planeta (FAO, 2015).

No Informe do Relator Especial das Nacións Unidas sobre o dereito á alimentación, Olivier De Schutter, di:

“O aumento da produción de alimentos é condición necesaria pero non suficiente para satisfacer as necesidades futuras. Non se lograrán avances importantes na loita contra a fame e a desnutrición si ese aumento non se combina con maiores ingresos e mellores medios de sustento para os máis pobres” (De Schutter, O., 2010, páx. 3).

A propia FAO no seu informe titulado "Como alimentar ao mundo en 2050", indica:

“As razóns polas que a fame e a mal nutrición poderían persistir a pesares de que exista unha oferta global suficiente a nivel nacional ou internacional son ben coñecidas e son a falta de oportunidades para obter ingresos por parte da poboación pobre e a ausencia dunhas medidas protectoras sociais eficaces" ( FAO, 2009, páx. 22).

Segundo a mesma organización ( FAO, 2012) a terceira parte da produción de alimentos pérdese. Na mesma dirección Delgado (2017) apunta cara o proceso de expansión das prácticas financeiras especulativas no terreo alimentario e a súas consecuencias: organización da produción, circulación e distribución de alimentos vinculadas a dinámicas específicas de acumulación de capital en cada ciclo ou fase do sistema, entendendo a comida como inversión e sendo o capital especulativo un dos principais actores na carreira polo control da terra cultivábel. Isto desemboca na erosión dos sistemas campesiños, 
no reforzo do dominio corporativo da cadea alimentar, do procesado e comercialización dos alimentos, é dicir, na creación dun mecanismo de apropiación de riqueza e poder sen necesidade de xestionar directamente os procesos produtivos.

Así pois, a fame e a mala nutrición de millóns de persoas non é debido a que a produción de alimentos sexa insuficiente, senón a que existe un problema de desigualdade na distribución e de falta de accesibilidade aos mesmos e tamén a que se substitúen cultivos para alimentar á poboación por monocultivos exportadores (Altieri, 2008). A exportación non debe ser considerada unha prioridade fronte a soberanía e seguranza alimentar, sen que isto implique unha negación do feito exportador dos excedentes. Ademais dáse unha degradación de bens fundamentais e unha apropiación e deterioro do patrimonio social e natural (Naredo, 2015). Por isto nace o concepto de soberanía alimentaria entendido como "o dereito dos pobos, dos seus Países ou Unións de Estados a definir súa política agraria e alimentaria, sen "dumping" fronte a países terceiros" (Via Campesina, 2003). Baixo esta perspectiva, tanto a aplicación dos conceptos de intensificación sustentábel, como os modelos de "land-sharing" ou "land-sparing"(1) (Perfecto e Vandermeer (2012) non son suficientes para resolver axeitadamente o desafío formulado, xa que son aproximacións parciais a un problema complexo tal como se comentou máis arriba, por centrarse basicamente na produción, sen atinxir a seguranza alimentar (dispoñibilidade e acceso aos alimentos), nin considerar de maneira específica aspectos fulcrais como os socioculturais ou a gobernanza. Ademais a intensificación sustentábel, segundo algúns autores, é unha das causas principais de perda de biodiversidade (Tilman et alii, 2011).

Dende a agro-ecoloxía considerase que se debe dar prioridade á soberanía alimentar e as producións destinadas ao comercio local. Tim Lang desenvolveu o concepto de "Food miles" como indicador do desenvolvemento sustentábel para poñer en evidencia os custes directos sociais, medioambientais e económicos do transporte dos alimentos e que normalmente están ocultos as consumidoras e consumidores (Lang, 2006). Así por exemplo, os efectos positivos da produción orgánica sobre o medio ambiente pode verse anulado polos efectos negativos derivados do transporte desta produción si se leva a cabo a moita distancia dos centros de consumo. Segundo Watkiss et alii ( 2005) no Informe final preparado por AEA Technology Environment para o Departamento de Medio Ambiente e Asuntos Rurais (DEFRA), a estimación dos custes directos -sociais, medioambientais e económicos- do transporte de alimentos superan os 9 mil millóns de libras anuais. En todo caso neste custe inflúe non só a distancia senón ademais o método de viaxe que se empregue. Por exemplo, moitas viaxes en automóbiles particulares para comprar no centro comercial teñen un impacto moito mais negativo que uns poucos camións de reparto para as tendas de barrio a onde se pode chegar de xeito doado, andando ou en bicicleta.

(1) O modelo "land sharing" define un territorio mixto para conservación/produción. O referente seria un territorio en mosaico, con sistemas produtivos sustentábeis e zonas intercaladas de conservación. Non implica a eliminación de zonas exclusivas para a preservación da biodiversidade. O modelo "land sparing" define un territorio onde unha parte é dedicada exclusivamente á conservación e outra parte á produción (nomeadamente intensiva). 
Esta relación tan importante está pouco estudada dende o ámbito científico, é dicir, que non sabemos cal é o impacto real da demanda sobre os produtores locais nos espazos agrícolas (Baysé-Lainé e Perrin, 2017). O estudo destas relacións fican fulcrais para diversos aspectos relacionados co sistema de produción, dende a necesidade de novas terras de cultivo, acompañamento da produción e circuítos de comercialización, identificación espacial para a localización do feito alimentar e influencia no desenvolvemento de sistemas socioculturais asociados á produción, comercialización e consumos, dieta alimentar, cuestións de xénero (ex. comunidades alimentares, ver da Silva, 2016), aplicación do concepto de degradación neutral do territorio ${ }^{(2)}$ (Kust et alii, 2017, Cowie et alii, 2018), ata a metodoloxía de estudo e caracterización a diferentes escalas, local e rexional. A produción/alimentación local ou de proximidade tamén mellora a economía local (creación de empregos), e inflúe mediante o subministro de produtos frescos e non procesados (ou menos procesados), na calidade da dieta alimentar. Esta perspectiva de produción-consumo non só favorece a actividade agrícola próxima á cidade, se non que implica un proceso de renovación da conexión entre o urbano e a agricultura (López García 2011), derivando no desenvolvemento de determinado senso de responsabilidade socioambiental nos/as consumidores/as (Galzki et alii, 2014). Ademais a volta aos circuítos curtos deriva da idea de retorno a un lugar espazo-temporal considerado como fonte natural de aprovisionamento. Por todo isto faise preciso ter unha visión de sistema socio-ecolóxico que inclúa as estratexias de produción e alimentación, fluxo de alimentos, capital natural, capital social, ou gobernanza (ver Yacamán e Mata, 2014). A produción agrícola, directamente dependente do capital natural, tamén require dos beneficios da inter-relación social.

Uns resultados óptimos en referencia ao desafío inicialmente proposto, soamente son esperábeis como consecuencia de interaccións complexas entre diferentes aspectos sociais e ecolóxicos, sendo ademais de especial aplicación na agricultura a escala familiar. Desta maneira, un escenario equilibrado (modelo "win-win") para a seguranza alimentar e calidade ambiental está asociado cun alto grado de equidade social no acceso a alimentos saudábeis, facilidade de acceso por parte das comunidades locais aos medios de produción (terra) e a un alto nivel de capital natural e social (Hanspach, 2017).

Partindo do amplo abano anterior, e como indicadores relacionados coas cuestións arriba expostas, neste traballo centrarémonos especificamente no balance consumo-produción e nos circuítos curtos.

\section{OBXECTIVOS}

Os obxectivos do presente traballo son realizar unha primeira aproximación para un maior coñecemento dos seguintes puntos:

2 O concepto de degradación neutral do territorio reflicte a necesidade de acadar o equilibrio entre terra cultivada e terra sen cultivar co o obxectivo de atanguer un impacto cero sobre a perda de biodiversidade, emisión/captación de gases e servicios eco-sistémicos de xeito xeral. 
- O potencial de produción de Galiza en relación cos datos dispoñíbeis de consumo. É dicir as posibilidades de autoabastecemento e de achegarse á soberanía alimentar.

- As posibilidades potenciais de abastecemento de proximidade mediante a comercialización local

En resume o obxectivo do presente traballo é dispoñer dunha análise inicial para o que utilizaremos só os datos estatísticos dispoñíbeis. Isto conduce necesariamente a que esta análise inicial teña limitacións. En traballos posteriores pretendemos completar e matizar o presente.

\section{METODOLOXÍA}

1. Calculo das necesidades de consumo "per cápita": a partires da base de dados do consumo en fogares (panel de consumo alimentario, os dados están territorializados a nivel de comunidade autónoma (Ministerio de Agricultura y Pesca, Alimentación y Medio Ambiente. Subdirección General de Estructura de la Cadena Alimentaria, 2017)). As necesidades totais de Galiza e de cada unha das comarcas obtéñense multiplicando o consumo "per cápita" polo numero de habitantes que corresponda. Este cálculo de necesidades pode estar subestimando o consumo total xa que posibelmente non se contempla aquela produción que é consumida na propia casa ou explotación e, sobre todo, non se recolle o consumo fóra do fogar. Pero nós consideramos que, dado que esta é unha primeira aproximación ao estado da cuestión, como dixemos, o cálculo realizado pode achegar información suficiente. En todo caso compre lembrar esta limitación á hora de valorar os datos que imos ofrecer a continuación.

O calculo de consumo de produtos elaborados fíxose tendo en conta a cantidade de produto sen elaborar necesaria para obter un quilo de produto elaborado. Por exemplo os quilos de queixo consumidos, tradúcense a litros de leite multiplicándoos polo volume medio de leite que se necesita para obter un quilo de queixo.

2. Capacidade de autoabastecemento nas grandes aglomeracións urbanas: análise das súas bacías alimentares entendidas como áreas xeográficas nas que os alimentos se producen e consumen (concepto no que insistiremos mais adiante).

2.1. Formulación das bacías alimentares das aglomeracións urbanas de Galiza. A bacía alimentar terrestre dunha cidade ou aglomeración urbana configurase como as propias comarcas (Xunta de Galicia, Decreto 65/1997, DOG Núm. 63, 3 abril) onde se asentan, e ademais o conxunto de comarcas limítrofes dentro dun circulo con radio aproximado de $80 \mathrm{~km}$ dende algunha das cidades incluídas na aglomeración urbana estudada. Inclúense as comarcas que teñen toda a súa extensión dentro deste circulo, mais tamén aquelas outras que só teñen unha parte da súa superficie dentro do mesmo e que, a maiores, cumpran a condición de que a súa cabeceira de comarca está a unha distancia da aglomeración urbana inferior aos $80 \mathrm{~km}$. Esta distancia 
médese por estrada xa que entendemos que no noso contexto sería a infraestrutura maioritariamente utilizada para o transporte dos alimentos. Si a bacía alimentaria se refire a dous centros urbanos, consideramos dentro da mesma á aquelas comarcas que están parcialmente dentro do círculo estudado e nas que ademais a distancia media ás dúas aglomeracións urbanas é inferior a $80 \mathrm{~km}$. Non se inclúen as comarcas das que son cabeceira outras cidades aínda que se sitúen dentro do circulo que abrangue a bacía alimentar, pois entendemos que desde a perspectiva do comercio de proximidade, estas comarcas deberían subministrar fundamentalmente ao centro urbano cabeceira da mesma.

2.2. Bacía alimentar reducida: configurada como as propias comarcas onde se asentan os núcleos urbanos e, ademais, o conxunto de comarcas limítrofes que se encontran dentro dun círculo cun radio aproximado de $50 \mathrm{~km}$ desde algunha das cidades incluídas na aglomeración urbana estudada. Neste caso só se inclúen as comarcas que teñen toda a súa extensión neste radio e non se consideran as que teñen por cabeceira outras cidades debido as razóns expostas anteriormente.

En calquera dos dous casos referímonos a bacías alimentares terrestres. A análise da utilización dos recursos alimentarios mariños precisa dun estudo mais pormenorizado e dunha definición previa do que se pode entender por bacía alimentar no mar.

3. As superficies actuais dedicadas a cada cultivo: Estatísticas do Instituto Galego de Estatísitica ( IGE ), "Encuesta de Superficies y Rendimientos de Cultivos (ESYRCE)" . Neste ultimo caso utilizáronse valores medios dos anos 2011 a 2016 incluídos.

3.1 Determinación da Superficie Agraria Utilizada (SAU). Asimílase á Superficie Agraria Utilizada a Superficie destinada a cultivos, prados e pasteiros. Moitos cultivos extensivos agrícolas non serían considerados tecnicamente como SAU por estar en terreos de monte (sistema forestal). Por outra banda, en varias estatísticas, a superficie destinada aos mesmos recollese nunha única categoría conxuntamente coa que se destina a prados permanentes, sen posibilidade de deslindar a que corresponde a cada un destes dous aproveitamentos.

4. Rendementos dos distintos cultivos: "Anuarios de Estatística Agraria" Consellería de Medio Rural, territorializados a nivel provincial. Rendementos medio, mínimo e máximo dos últimos anos publicados ( 2011 a 2015).

5. Necesidades de superficie: Razón entre as necesidades de consumo dunha comarca ou do conxunto de Galiza, e os rendementos dos cultivos.

5.1. Consideramos como superficie máxima necesaria aquela que seria precisa tendo en conta as necesidades máximas de consumo e os rendementos de cultivos no nivel mais baixo do rango de rendementos atopados. Pola contra a superficie mínima necesaria está calculada no suposto de que os rendementos dos cultivos se sitúen no valor mais alto do rango de rendementos atopados e as necesidades de consumo sexan as mínimas estimadas. 
6. Necesidades de consumo de produtos animais procedentes da gandería ligada á terra expresadas como necesidades de superficie para contribuír á alimentación deste gando: produtos forraxeiros (millo, pradarías), prados e pasteiros baixo a hipótese de que se manteñan os actuais sistemas produtivos.

Como non todas as cabezas de gando herbívoro son equiparábeis (vacas en produción, xovencas, becerros, vacas reprodutoras, de reposición, animais en cebo, gando ovino e caprino), utilizouse como unidade de medida a Unidade de Gando Maior (UGM) ou Unidade de Gando (UG). Para determinalas equivalencias de cada tipo de animal empregáronse as táboas de conversión correspondentes dispostas polo Censo Agrario (INE, 2009) e polo Real Decreto 1131/2010, de 10 de setembro (Ministerio de Medio Ambiente y Medio Rural y Marino, 2010).

Nalgún caso foi preciso facer algunha pequena adaptación e/ou interpretación xa que as categorías que utilizan as estatísticas para clasificar o gando e as que figuran nas táboas de conversión de cada tipo de animais en UGM (ou UG) non coinciden plenamente.

Por outra banda, como non todas as superficies dedicadas á producir para alimentar ao gando teñen o mesmo rendemento produtivo nin o valor nutritivo é o mesmo, optouse por poñelas todas en relación só a unha delas. Partindo da hipótese de que si toda a superficie dedicada á alimentación do gando fora do mesmo cultivo, a superficie que lle correspondería aos diferentes tipos de gando (vacún de leite, vacún de carne e ovino-cabrún) debería ser proporcional ás UGM que achega cada un deles ao total. Finalmente tamén se calculou a relación entre os distintos aproveitamentos dedicados á alimentación do gando, procedendo a estimar a porcentaxe de superficie de cada tipo de aproveitamento que sería imputábel a cada tipo de gando.

7. Índices de comparación entre distintos espazos (comarcas ou bacías alimentares por exemplo).

7.1. Índice de auto-abastecemento (Iaa), definido como a porcentaxe de poboación que pode ser abastecida coa produción do país, baixo a hipótese de que se manteñan os niveis de consumo e produción actual.

7.2. Relación entre a superficie actual e a necesaria (resan), definido como o cociente entre a superficie actualmente dispoñíbel para un grupo de cultivos e a superficie que sería necesaria para abastecer deste grupo de cultivos ao total da poboación. Tamén se aplicará ao conxunto dos cultivos e aproveitamentos.

7.3. Balance relativo (Br), definido como a diferenza entre a superficie actualmente dispoñíbel e a necesaria para auto-abastecer do conxunto de cultivos estudados ao total da poboación do pais, da comarca ou da bacía alimentar, expresado en porcentaxe da superficie destinada a cultivos, prados e pasteiros en cada un dos territorios onde se aplica. 


\section{RESULTADOS}

4.1. O balance consumo-produción para o conxunto de Galiza: situación actual e perspectivas.

A fig. 1 reflicte a relación entre consumo da poboación e a produción actual de Galiza para os produtos de orixe agrícola ou gandeira. Na táboa I recollese o índice de auto-abastecemento definido na metodoloxía.

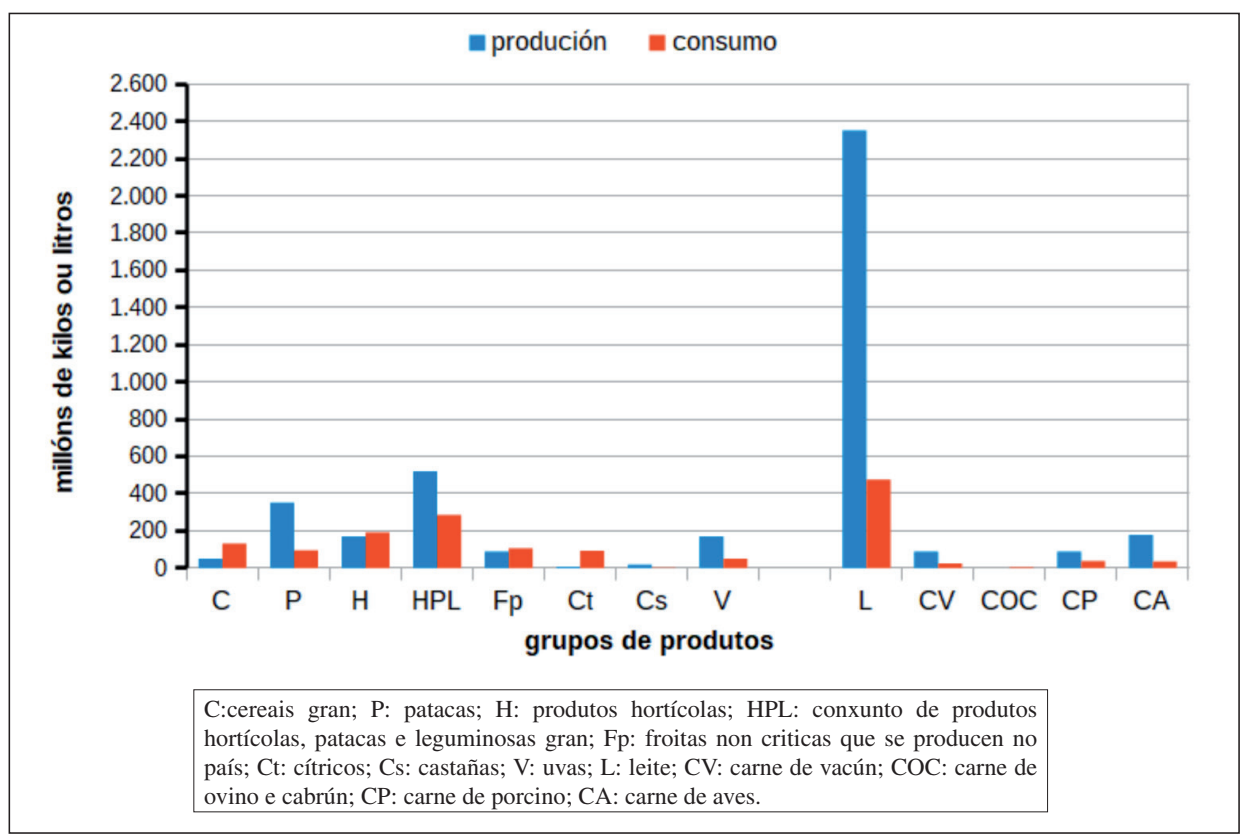

Figura 1. Relación entre consumo actual da poboación e a produción actual de Galiza.

Táboa I. Índice de autoabastecemento para Galiza de animais e vexetais.

\begin{tabular}{|l|r|r|c|}
\hline Grupo de produtos vexetais & \multicolumn{1}{|c|}{ Iaa } & Grupo de produtos animais & Iaa \\
\hline Cereais gran & $37 \%$ & Leite de vacún & $495 \%$ \\
\hline Patacas & $372 \%$ & Carne vacún & $367 \%$ \\
\hline Produtos hortícolas & $89 \%$ & Carne de ovino e cabrún & $11 \%$ \\
\hline $\begin{array}{l}\text { Conxunto de produtos hortícolas, pataca e } \\
\text { leguminosas gran }\end{array}$ & $183 \%$ & Carne de porcino & $240 \%$ \\
\hline Froitas non cítricas que se producem no país & $84 \%$ & Carne de aves & $507 \%$ \\
\hline Cítricos & $7 \%$ & & \\
\hline Castañas & $596 \%$ & & \\
\hline Uvas & $345 \%$ & & \\
\hline
\end{tabular}

Iaa é o índice de autoabastecemento que se define como a porcentaxe de poboación que pode ser abastecida coa produción do país, baixo a hipótese de que se manteñan os niveis de consumo e produción actual. 
As fig. $2 \mathrm{a}$ e $2 \mathrm{~b}$ reflicten un balance entre a superficie necesaria para abastecer ao conxunto da poboación de Galiza e a superficie actualmente dedicada a cada grupo de cultivos. Observase que para achegarnos á soberanía alimentar naqueles produtos que somos capaces de producir, dispoñemos dun un balance global positivo de pouco mais de 470 mil ha. Sen embargo este balance global encubre déficits parciais.

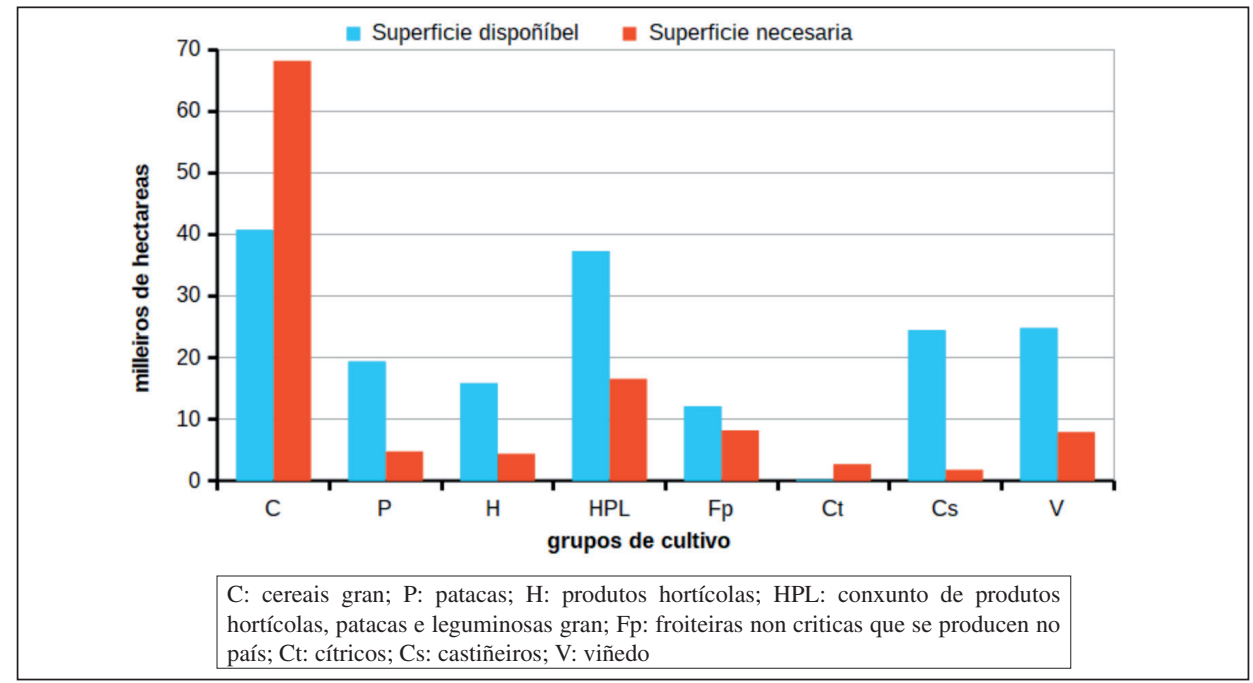

Figura 2a. Superficie necesaria para cubrir o consumo interno de Galiza e superficie actualmente dispoñíbel (alimentos para consumo humano directo).

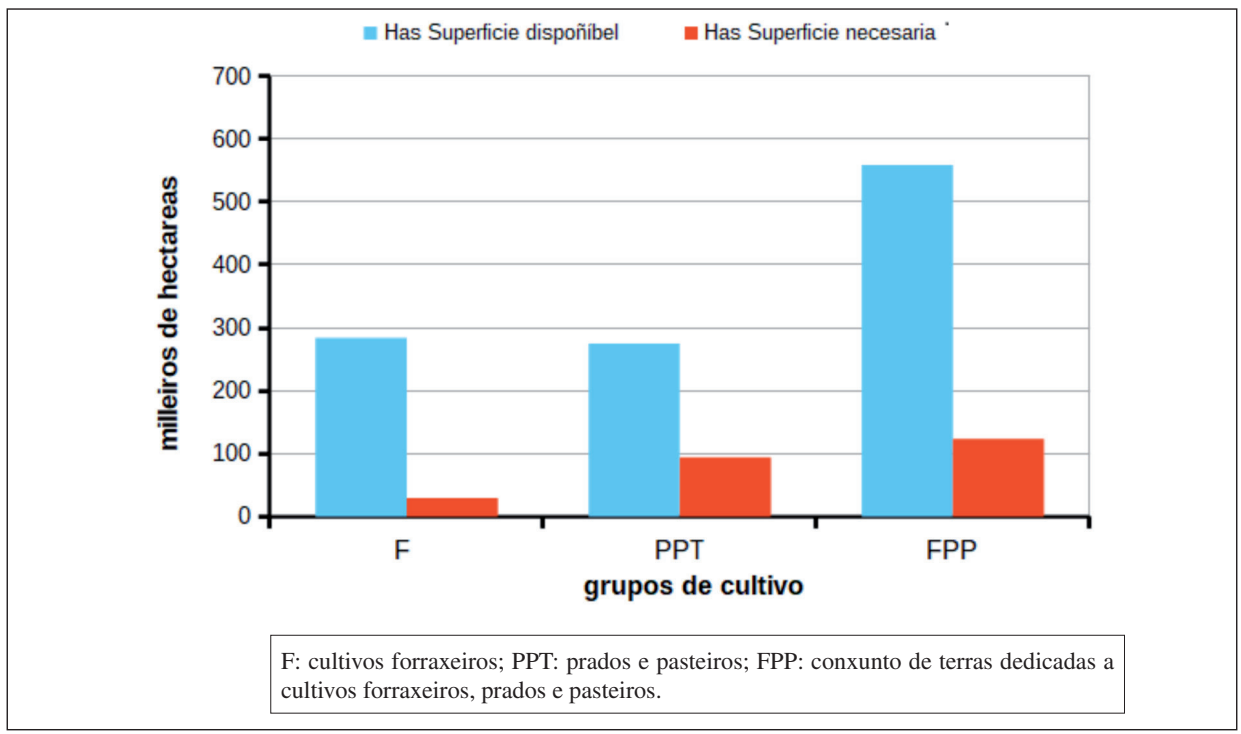

Figura 2b. Superficie necesaria para cubrir o consumo interno de Galiza e superficie actualmente dispoñíbel (alimentos para consumo do gando) 
Existen cultivos ou aproveitamentos que na actualidade utilizan no seu conxunto preto de 500.000 ha de terras a maiores das necesarias para o abastecemento da poboación total de Galiza. É o caso dos cultivos de horta, patacas, viñas, cultivos forraxeiros, prados e pasteiros. Inclúese nesta cifra as máis de 10.000 ha de castiñeiros que ao mellor teñen que ser contempladas tamén desde outras perspectivas. Sen embargo, existen cultivos ou aproveitamentos que precisarían usar arredor de 30.000 ha de terra a maiores das que están utilizando na actualidade. Este sería o caso dos cereais gran e cítricos, fundamentalmente.

Na táboa II calculamos a relación entre a superficie actual e a necesaria (resan) que temos definido na metodoloxía.

Táboa II. Relación entre a superficie actualmente dispoñíbel e a superficie necesaria para autoabastecer á poboación (resan)

\begin{tabular}{|l|r|l|c|}
\hline $\begin{array}{l}\text { Grupo de produtos cultivos para alimentación } \\
\text { humana directa }\end{array}$ & resan & \multicolumn{1}{|c|}{ Grupo de cultivos } & resan \\
\hline Cereais gran & $60 \%$ & Cultivos forraxeiros & $976 \%$ \\
\hline Patacas & $405 \%$ & Prados e pasteiros & $292 \%$ \\
\hline Produtos hortícolas & $362 \%$ & $\begin{array}{l}\text { Conxunto de terras dedicadas } \\
\text { a cultivos forraxeiros, prados } \\
\text { e pasteiros }\end{array}$ & $453 \%$ \\
\hline $\begin{array}{l}\text { Conxunto de terras dedicadas a cultivos } \\
\text { hortícolas, pataca e leguminosas gran }\end{array}$ & $225 \%$ & Carne de porcino & $240 \%$ \\
\hline Froitas non cítricas que se producem no país & $147 \%$ & Carne de aves & $507 \%$ \\
\hline Cítricos & $7 \%$ & & \\
\hline Castiñeiros & $1359 \%$ & & \\
\hline Viñedo & $313 \%$ & & \\
\hline Superficie total de terras de cultivo, prados e pasteiros - resan: $309 \%$ & \\
\hline
\end{tabular}

resan: relación entre a superficie actual e a necesaria. Calculase dividindo a superficie actualmente dispoñíbel para un grupo de cultivos e a superficie que sería necesaria para abastecer deste grupo de cultivos ao total da poboación.

Hai que ter en conta que nalgún caso, fundamentalmente no das froitas e hortalizas, sempre haberá produtos dos que nonos poderiamos autoabastecer, ben porque non se poden cultivar en Galiza, ou só se poden facer con moi baixos rendementos.

Sen embargo tamén hai que ter en conta que as necesidades nestes casos dependen en grande medida dos hábitos de consumo que poderían ou mesmo deberían ser modificados. De esta opinión son distintos/as autores/as (Winograd, M., 2012), organizacións (Consumo Responsable, 2017) e en certa maneira o propio ministerio do ramo que promociona o consumo de froitas de tempada (Ministerio de Agricultura y Pesca, Alimentación y Medio Ambiente, 2017).

No caso de que houbese un cambio de hábitos dirixidos a consumir menos froitas tropicais, exóticas ou mediterráneas e menos produtos hortícolas fora de tempada, repercutiría nun aumento de consumo das froitas e hortalizas do país. Isto implicaría que seria preciso dedicar á froita e á horta maior superficie da que temos estimada. Non semella 
que sexa un reto demasiado difícil no caso de querer asumilo, mais seria preciso analizalo polo miúdo.

Outro aspecto que pode facer variar as necesidades de superficie é o sistema de produción. Así por exemplo no caso de que o sistema de produción de gando, sobre todo no vacún de leite, se fixera máis extensivo de maneira que se reducira o consumo de concentrados e se aumentara o consumo de forraxe, podería ser necesaria reducir a carga gandeira e se cadra a produción, mais tamén neste caso os dados apuntan a que existe marxe suficiente como para acometer esta extensificación e que os problemas a resolver serían doutro tipo.

Podemos dicir pois que na actualidade temos "superávit" no relativo á superficie produtiva destinada a alimentación do gando. Tendo presente que a SAU asociada a produción de carne é un dos principais factores protagonistas da alteración dos recursos silvestres $(60 \%$ da biodiversidade global perdese pola transformación de terras para a produción de carne, WWF (2017)), ademais de supor un consumo excesivo de proteína animal na dieta humana con consecuencias prexudiciais para a saúde (ver a revisión de Barriuso, 2016), estamos ante un escenario que dende a perspectiva tanto da soberanía como do concepto de sustentabilidade alimentar, abre un abano de posibilidades para a troca de superficies de uso gandeiro por outro tipo de cultivos dos cales somos deficitarios, conxuntamente coa recuperación de superficie procedente dos procesos de reforestación de terras agraria (Corbelle e Crecente, 2008).

A táboa III reflicte un balance entre a superficie necesaria para cubrir as nosas necesidades de consumo e a que actualmente se dedica a cada grupo de cultivos, mais no lugar de utilizar os valores medios, ofrecemos un rango dentro do cal se pode mover tanto a superficie necesaria como a actualmente destinada aos mesmos.

Táboa III. Rango de valores entre os que se move a superficie necesaria para cubrir o consumo interno de Galiza de determinados grupos de cultivos e a superficie actualmente destinada aos mesmos

\begin{tabular}{|l|l|l|}
\hline Grupo de produtos & Superficie dispoñíbel & Superficie necesaria \\
\hline Cereais gran & de 19.026 a 22.948 ha & de 36.464 a 11.9292 ha \\
\hline Patacas & de 17.375 a 18.134 hs & de 3.835 a 5.717 ha \\
\hline Cultivos hortícolas & de 3.942 a 4.202 ha & de 3.831 a 5.305 ha \\
\hline $\begin{array}{l}\text { Conxunto de terras dedicadas a cultivos hortícolas, } \\
\text { pataca e leguminosas gran }\end{array}$ & de 22.512 a 23.719 ha & de 14.744 a 18.722 ha \\
\hline Froitas non cítricas que se producem no país & de 6.555 a 6.803 ha & de 6.485 a 11.372 ha \\
\hline Cítricos & 192 ha & de 2.678 a 3.373 ha \\
\hline Castiñeiros & de 10.687 a 10.932 ha & de 1.062 a 4.485 ha \\
\hline Viñedo & de 26.973 a 27.256 ha & de 6.655 a 10.631 ha \\
\hline Cultivos forraxeiros & de 221.784 a 228.434 ha & de 19.465 a 41.236 ha \\
\hline Prados e pasteiros & de 440.119 a 445.162 ha & de 14.965 a 35.519 ha \\
\hline $\begin{array}{l}\text { Conxunto de terras dedicadas a cultivos forraxeiros, } \\
\text { prados e pasteiros }\end{array}$ & de 661.903 a 673.596 ha & de 34.430 a76.756 ha \\
\hline Superficie total de cultivo, prados e pasteiros & de 842.517 a 859.700 ha & de 84.875 a 241.258 ha \\
\hline
\end{tabular}




\subsection{O balance consumo-produción para as comarcas de Galiza}

A definición de "comercialización local" admite varias interpretacións de acordo co contexto, o pais, o contorno, os grupos sociais e mesmo o tipo de produto. (Kloppenburg et alii, 1996; Allen, A., 2003; Du Puis \& Goodman, 2005; Born \& Purcell, 2006; Weber \& Matthews, 2008; Alier \& Jusmet, 2013; DeLind, 2011). En sentido amplo podemos entender o concepto de "comercialización local" como a que se da na localidade e o seu contorno mais inmediato. En Galiza podiamos asimilalo a aquela que se produce no nivel da comarca natural.

Para os cálculos utilizamos os mesmos datos de rendementos de cultivos que foron empregados para o conxunto de Galiza que, como dixemos, están territorializados só ate o nivel provincial. Isto é unha simplificación ou limitación que hai que ter en conta á hora de interpretar os resultados.

$\mathrm{Na}$ táboa IV faise un resume e observase que o numero de persoas con capacidade para ser autoabastecidas dentro da súa comarca é moi importante, sendo maior para os produtos de horta, viñedo ou patacas e menor para cereais e froitas.

Táboa IV. Habitantes que poderían ser autoabastecidos/as polas producións obtidas para determinados grupos de cultivo dentro da comarca na que viven

\begin{tabular}{|l|c|c|}
\hline Grupo de produtos & $\begin{array}{c}\text { Número de habitantes } \\
\text { autoabastecidos/as dentro da súa } \\
\text { propia comarca }\end{array}$ & \% total de Galiza \\
\hline Cereais gran & 453.156 & $16 \%$ \\
\hline Patacas & 1.745 .541 & $63 \%$ \\
\hline $\begin{array}{l}\text { Conxunto de terras dedicadas a cultivos } \\
\text { hortícolas, pataca e leguminosas gran }\end{array}$ & 1.952 .621 & $70 \%$ \\
\hline Froitas non cítricas que se producen no país & 1.280 .335 & $56 \%$ \\
\hline Viñedo & 1.541 .909 & $58 \%$ \\
\hline $\begin{array}{l}\text { Conxunto de terras dedicadas a cultivos } \\
\text { forraxeiros, prados e pasteiros }\end{array}$ & 1.619 .336 & $56 \%$ \\
\hline
\end{tabular}

No caso de pretender o autoabastecemento dos/as habitantes dentro da súa comarca natural, podemos diferenciar os seguintes casos:

A. 3 comarcas dispoñen de menos superficie destinada a cultivos, prados e pasteiros que a necesaria para abastecer á súa poboación. Representan só o 6\% do total e correspóndense coas zonas mais poboadas e con áreas costeiras: comarcas de Vigo, A Coruña e O Morrazo.

B. 9 comarcas dispoñen de mais superficie destinada a cultivos, prados e pasteiros que a necesaria nunha porcentaxe que é inferior á metade da actualmente dispoñíbel (entre un $9 \%$ e un $49 \%$ a maiores). Representan o $17 \%$ do total: comarcas de Santiago, O Condado, O Baixo Miño, Ferrol, Ourense, O Salnés, Pontevedra, Muros e o Barbanza. 
C. 41 comarcas dispoñen de mais superficie destinada a cultivos, prados e pasteiros que a necesaria nunha porcentaxe que supera a metade da actualmente dispoñíbel (entre un $61 \%$ e un $97 \%$ ). Son o resto das comarcas de Galiza que representan o $77 \%$ do total.

\subsection{O balance consumo-produción nas bacías alimentares das aglomeracións urbanas}

Os principais problemas de autoabastecemento poden xurdir nas aglomeracións urbanas, no caso de que dito obxectivo se pretendera conseguir cun comercio de proximidade. Como xa dixemos na Galiza podemos asimilar este comercio de proximidade co que se da ao nivel de comarca natural. Sen embargo nas grandes aglomeracións urbanas poderíase considerar o concepto de circuítos longos de proximidade: dous intermediarios nos circuítos curtos (Baysse-Lainé e Perrin, 2017). En todo caso si falamos de contorno xeográfico, semella mais acaído o termo de bacías alimentares entendidas como áreas xeográficas nas que os alimentos se producen e consumen e nas que se da unha sinerxía entre a sustentabilidade do agro-ecosistema, a economía rural e a seguridade alimentaria (Zumkehr \& Campbell, 2015).

Neste sentido acostumase a considerar mercado de proximidade aquel que se da nun radio de acción de 100 quilómetros como máximo. Zumkehr e Campbell (2015) utilizan radios de 50 millas (80 km aproximadamente) e 100 millas (161 km aproximadamente) para analizar as bacías de alimentación no seu estudio sobre o potencial dos cultivos locais para cubrir a demanda de alimentos en Estados Unidos.

Neste traballo formúlanse as bacías alimentares terrestres das aglomeracións urbanas de Galiza do xeito que se indicou anteriormente no apartado de metodoloxía. A superficie destas bacías así definidas aproximase ao valor das máis pequenas das estudadas por Zumkehr e Campbell (2015) en Estados Unidos ou Baisse-Lainé e Perrin (2017) en Millau-Francia.

A continuación recollemos os datos das bacías alimentares das aglomeracións urbanas de Galiza. O balance de superficies actuais e as necesarias faise cos valores medios de consumos e rendementos. Aquí temos que facer a mesma consideración que xa temos feito no caso das comarcas. Para os cálculos utilizamos os dados de rendementos de cultivos que se empregaron para o conxunto Galiza que, como dixemos, están territorializados só ate o nivel provincial e isto haberá que telo en conta ao interpretar os resultados.

\subsubsection{Vigo-Pontevedra}

a. Bacía alimentar terrestre reducida, composta polas comarcas do Barbanza, Sar, Baixo Miño, O Condado, O Morrazo, A Paradanta, Pontevedra, O Salnés, Tabeirós-Terra de Montes e Vigo. Ten unha extensión de preto de 389.180 ha e unha poboación 997.345 habitantes. A superficie de cultivo actual, mirada globalmente, é insuficiente para cubrir as necesidades da poboación. 
b. Bacía alimentar non reducida, inclúe ademais das comarcas anteriores as de A Barcala, Muros, Noia, Xallas, O Carballiño, O Ribeiro, Terra de Celanova e Deza. Abrangue unha superficie 799.040 ha e ten que abastecer a unha poboación de 1.189 .903 persoas.

Como se observa na táboa V, para cubrir as súas necesidades sería preciso dispoñer dalgunha superficie máis dedicada ás froiteiras (unhas 130 ha) e habería que explorar a posibilidade de aumentar o número de cítricos. En todo caso o principal déficit está na superficie dedicada a cereais gran xa que se precisaría dispoñer de arredor de 19.000 ha a maiores. Polo demais, no resto dos grupos de cultivo agás determinadas excepcións, a bacía alimentar dispón de superficie dabondo para abastecer a súa poboación. Existe mesmo un importante excedente global que podería servir, nalgún caso, para un cambio de uso das terras a fin de destinalas a aproveitamentos de cultivos con déficit de superficie.

Táboa V. Balance entre superficies de cultivo actuais e as superficies necesarias para autoabastecer á poboación nas bacías alimentares terrestres de Vigo-Pontevedra

\begin{tabular}{|l|c|c|c|}
\hline Grupos de cultivos & ud & Bacía alimentar & $\begin{array}{c}\text { Bacía alimentar } \\
\text { REDUCIDA }\end{array}$ \\
\hline Cereais gran & ha & -19.009 & -18.066 \\
\hline Patacas & ha & 2.598 & 1.092 \\
\hline Cultivos hortícolas & ha & 2.740 & 1.413 \\
\hline $\begin{array}{l}\text { Conxunto de cultivos hortícolas, patacas e leguminosas } \\
\text { gran }\end{array}$ & ha & 2.695 & 114 \\
\hline Froiteiras que se cultivan no país & ha & -131 & -696 \\
\hline Conxunto de cultivos forraxeiros, prados e pasteiros & ha & 84.358 & 17.840 \\
\hline BALANCES GLOBAIS & ha & -35.261 & -31.403 \\
\hline Superficie necesaria de cultivos deficitarios & ha & 81.026 & 8.981 \\
\hline Balance global & $\%$ & $55 \%$ & $14 \%$ \\
\hline $\begin{array}{l}\text { Br (Balance relativo) expresado en } \% \text { da superficie } \\
\text { total dedicada a cultivos, prados e pasteiros }\end{array}$ & $\%$ & \multicolumn{2}{|c|}{} \\
\hline
\end{tabular}

\subsubsection{A Coruña-Ferrol}

a. Bacía alimentar terrestre reducida está composta polas comarcas de Bergantiños, Betanzos, A Coruña, Eume, Ferrol, Ordes e Ortegal. Ten unha extensión de mais de 420.000 ha cunha poboación de case 745.108 persoas.

b. A bacía alimentar non reducida inclúe ademais das comarcas anteriores as de A Barcala, O Sar, Terra de Melide, Terra de Soneira, Xallas, A Mariña Occidental e a Terra Chá. Abrangue unha superficie de 803.850 ha e ten que abastecer a unha poboación de 890.093 persoas.

Na táboa VI reflíctese o balance entre as superficies de cultivo actuais e as necesarias para cubrir o consumo das persoas que viven nas bacías alimentares de A CoruñaFerrol. Para autoabastecer á súa poboación nos grupos de cultivo analizados calquera delas dispón de superficie dabondo, agás no caso dos cereais gran, que precisarían dis- 
poñer a maiores de 13.000 ha aproximadamente. O balance global indica que existe mais superficie da necesaria, oscilando o superávit aproximadamente entre 67.000 e 174.000 ha segundo consideremos a bacía reducida ou a máis ampla.

Táboa VI. Balance entre superficies de cultivo actuais e as superficies necesarias para autoabastecer á poboación nas bacías alimentares terrestres de Coruña-Ferrol

\begin{tabular}{|l|c|c|c|}
\hline Grupos de cultivos & ud & Bacía alimentar & $\begin{array}{c}\text { Bacía alimentar } \\
\text { REDUCIDA }\end{array}$ \\
\hline Cereais gran & ha & -13.317 & -13.402 \\
\hline Patacas & ha & 3.696 & 2.261 \\
\hline Cultivos hortícolas & ha & 3.185 & 1.961 \\
\hline $\begin{array}{l}\text { Conxunto de cultivos hortícolas, patacas e leguminosas } \\
\text { gran }\end{array}$ & ha & 5.315 & 2.850 \\
\hline Froiteiras que se cultivan no país & ha & 1.784 & 1.433 \\
\hline Conxunto de cultivos forraxeiros, prados e pasteiros & ha & 181.168 & 77.259 \\
\hline BALANCES GLOBAIS & ha & -26.370 & -22.499 \\
\hline Superficie necesaria de cultivos deficitarios & ha & 174.419 & 67.424 \\
\hline Balance global & $\%$ & $78 \%$ & $62 \%$ \\
\hline $\begin{array}{l}\text { Br (Balance relativo) expresado en } \% \text { da superficie } \\
\text { total dedicada a cultivos, prados e pasteiros }\end{array}$ & & \\
\hline
\end{tabular}

\subsubsection{Santiago de Compostela}

a. A bacía alimentar terrestre de Santiago de Compostela ten unha superficie de máis de 915.690 ha e nela viven 882.008 persoas. Está composta polas comarcas de Arzúa, A Barcala, Muros, Noia, Ordes, Santiago, O Sar, Xallas, Caldas, Tabeirós-Terra de Montes, Barbanza, Bergantiños, Betanzos, Fisterra. Terra de Melide; Terra de Soneira, A Ulloa, O Carballiño, Deza, O Morrazo e O Salnés.

b. A bacía mais reducida abrangue só as dez primeiras. Ocupa 399.780 ha cunha poboación de 373.976 habitantes.

A diferenza entre as actuais superficies de cultivo e as que serían necesarias para autoabastecer á súa poboación recollese na táboa VII. Para cubrir as necesidades de consumo sería preciso dispoñer de mais superficie dedicada ao cultivo de cereais gran, mais menor medida que nos dous casos anteriores que se levan analizado. Só se precisarían aproximadamente entre 3.000 e 8.000 ha a maiores.

En canto á superficie que actualmente se dedica cultivos forraxeiros, prados e pasteiros, detéctanse aproximadamente entre 92.000 e 200.000 ha a maiores, é dicir, que excede moi amplamente a necesaria para autoabastecer á poboación.

En todo caso nas bacías alimentares de Santiago de Compostela existe máis superficie de cultivo, prados e pasteiros que a necesaria para abastecer a súa poboación, sendo o superávit bastante elevado pois representa máis do $80 \%$ da existente nas comarcas que forman parte delas. 
Táboa VII. Balance entre superficies de cultivo actuais e as superficies necesarias para autoabastecer á poboación nas bacías alimentares terrestres de Santiago de Compostela

\begin{tabular}{|l|c|c|c|}
\hline Grupos de cultivos & ud & Bacía alimentar & $\begin{array}{c}\text { Bacía alimentar } \\
\text { REDUCIDA }\end{array}$ \\
\hline Cereais gran & ha & -7.643 & -3.166 \\
\hline Patacas & ha & 5.320 & 1.506 \\
\hline Cultivos hortícolas & ha & 5.587 & 2.768 \\
\hline $\begin{array}{l}\text { Conxunto de cultivos hortícolas, patacas e leguminosas } \\
\text { gran }\end{array}$ & ha & 9.553 & 3.619 \\
\hline Froiteiras que se cultivan no país & ha & 938 & 247 \\
\hline Conxunto de cultivos forraxeiros, prados e pasteiros & ha & 199.106 & 92.253 \\
\hline BALANCES GLOBAIS & ha & -18.758 & -9.180 \\
\hline Superficie necesaria de cultivos deficitarios & ha & 210.494 & 96.117 \\
\hline Balance global & $\%$ & $81 \%$ & $82 \%$ \\
\hline $\begin{array}{l}\text { Br (Balance relativo) expresado en } \% \text { da superficie } \\
\text { total dedicada a cultivos, prados e pasteiros }\end{array}$ & & \\
\hline
\end{tabular}

\subsubsection{Lugo}

a. A bacía alimentar terrestre reducida está composta polas comarcas de Lugo, A Ulloa e Terra de Melide. Ten unha superficie de 214.790 ha e nela viven 142.759 persoas.

b. A bacía non reducida inclúe ademais as comarcas de Arzúa, Betanzos, Eume, Os Ancares, Chantada, A Fonsagrada, A Mariña Central, A Mariña Oriental, Meira, Quiroga, Sarria, Terra Chá, Terra de Lemos e Deza. Neste caso a superficie da bacía é de 1.245.720 ha e ten que abastecer a 458.811 habitantes.

Táboa VIII. Balance entre superficies de cultivo actuais e as superficies necesarias para autoabastecer á poboación nas bacías alimentares terrestres de Lugo

\begin{tabular}{|l|c|c|c|}
\hline Grupos de cultivos & ud & Bacía alimentar & $\begin{array}{c}\text { Bacía alimentar } \\
\text { REDUCIDA }\end{array}$ \\
\hline Cereais gran & ha & -3.537 & -1.335 \\
\hline Patacas & ha & 4.752 & 1.025 \\
\hline Cultivos hortícolas & ha & 4.065 & 964 \\
\hline $\begin{array}{l}\text { Conxunto de cultivos hortícolas, patacas e leguminosas } \\
\text { gran }\end{array}$ & ha & 8.259 & 1.675 \\
\hline Froiteiras que se cultivan no país & ha & 2.583 & 121 \\
\hline Conxunto de cultivos forraxeiros, prados e pasteiros & ha & 289.317 & 70.492 \\
\hline BALANCES GLOBAIS & ha & -8.533 & -2.356 \\
\hline Superficie necesaria de cultivos deficitarios & ha & 305.854 & 71.393 \\
\hline Balance global & $\%$ & $92 \%$ & $90 \%$ \\
\hline $\begin{array}{l}\text { Br (Balance relativo) expresado en \% da superficie } \\
\text { total dedicada a cultivos, prados e pasteiros }\end{array}$ & $\%$ \\
\hline
\end{tabular}


Na táboa XI observase que para cubrir as necesidades da súa poboación a bacía alimentar de Lugo amosa un menor déficit de superficie para o cultivo de cereais gran que as anteriores (aproximadamente $3.600 \mathrm{ha}$ ).

Como no caso da bacía alimentar de Santiago de Compostela, a superficie actualmente destinada a cultivos forraxeiros, prados e pasteiros é claramente superior á necesaria para auto-abastecer á poboación (aproximadamente 300.000 ha a maiores na bacía máis ampla). Dúas razóns poderían dar lugar a esta situación. Por unha banda a inclusión das amplas comarcas nas que se encontran as montañas orientais de Galiza. Pola outra, a cualificación como prados e pasteiros de terreos que sinxelamente non teñen aproveitamento porque xa non se traballan.

\subsubsection{Vigo-Pontevedra}

a. A bacía alimentar terrestre ten unha superficie de 1.179.740 ha. Nela viven arredor de 560.291 persoas. Está integrada polas comarcas de Chantada, Allariz-Maceda, O Carballiño, Ourense, O Ribeiro, Terra de Caldelas, Terra de Celanova, A Paradanta, Arzúa, Quiroga, Sarria, Terra de Lemos, A Ulloa, Baixa Limia, A Limia, Terra de Trives, Verín, Caldas, O Condado, Deza e Tabeirós-Terra de Montes.

b. A bacía máis reducida agrupa só as oito primeiras comarcas. Abrangue 358.240 ha para subministrar alimento a unha poboación de 259.491 habitantes.

Na táboa XII observase que a superficie de cultivo é suficiente para cubrir as necesidades de consumo das persoas que viven na bacía alimentar de Ourense. Só podería ser necesario aumentar a superficie destinada a cereais gran (arredor de 2.600 ha máis) no caso de que se pretenderan cubrir só coas comarcas da bacía alimentar reducida. En todo caso no balance global a superficie actual supera á necesaria con moita marxe.

Táboa IX. Balance entre superficies de cultivo actuais e as superficies necesarias para autoabastecer á poboación nas bacías alimentares terrestres de Ourense

\begin{tabular}{|l|c|c|c|}
\hline Grupos de cultivos & ud & Bacía alimentar & $\begin{array}{c}\text { Bacía alimentar } \\
\text { REDUCIDA }\end{array}$ \\
\hline Cereais gran & ha & 8.262 & -2.581 \\
\hline Patacas & ha & 7.761 & 2.008 \\
\hline Cultivos hortícolas & ha & 4.497 & 1.565 \\
\hline $\begin{array}{l}\text { Conxunto de cultivos hortícolas, patacas e leguminosas } \\
\text { gran }\end{array}$ & ha & 11.251 & 3.061 \\
\hline Froiteiras que se cultivan no país & ha & 1.865 & 703 \\
\hline Conxunto de cultivos forraxeiros, prados e pasteiros & ha & 206.157 & 47.887 \\
\hline BALANCES GLOBAIS & & \multicolumn{2}{|c|}{} \\
\hline Superficie necesaria de cultivos deficitarios & ha & -7.920 & -5.911 \\
\hline Balance global & ha & 248.987 & 56.300 \\
\hline $\begin{array}{l}\text { Br (Balance relativo) expresado en } \% \text { da superficie } \\
\text { total dedicada a cultivos, prados e pasteiros }\end{array}$ & $\%$ & $89 \%$ & $79 \%$ \\
\hline
\end{tabular}




\section{CONCLUSIÓNS}

\subsection{Análise metodolóxica}

5.1.1. As informacións fornecidas polas bases dados dispoñibles precisan ser reinterpretadas e re-calculadas, xa que en certos casos non hai información axeitada para determinadas variábeis (ex. distintos tipoloxía de cabezas de gando, relación tipos de cultivos e rendemento e valor nutritivo).

5.1.2. A relación entre superficie de consumo e a superficie de produción parece ser un bo indicador xeral para caracterizar o estado xeral da soberanía alimentar. Mais é importante traballar con indicadores parciais, que en función dos déficits atopados e tendo presente información sobre necesidades nutricionais, gasto e aproveitamento enerxético (emerxía, exergía, Tello et alii, 2008; Pérez-Neira e Grolmus-Venegas, 2018) subministren unha maior información específica e de oportuna aplicabilidade: índices de consumo/ produción para cereais, para froitas e hortalizas e para carne por separado.

\subsection{Balance de consumo-produción}

5.2.1. Disponse dun balance global positivo naquilo que se pode producir en Galiza e mantendo os actuais hábitos de consumo, que sen embargo agacha déficits parciais en determinados grupos de cultivos, fundamentalmente nos cereais gran e froiteiras. Esta conclusión non semella que estea en consonancia co feito de que a balanza comercial agroalimentar da Galiza sexa negativa. Podemos aventurar que isto pode ser debido a varios factores. En primeiro lugar a balanza agroalimentar médese en euros e neste artigo os balances consumo-produción dánse en quilos, litros ou hectáreas. En segundo lugar, neste traballo faise un balance sobre aquilo que se pode producir en Galiza, mais a balanza comercial refírese ao total do consumo. En terceiro lugar, as diferenzas de custes entre os produtos que se venden ao exterior e os que é necesario comprar tamén poden influír en que a balanza agroalimentar sexa negativa. Finalmente, e relacionado co anterior, puidera ocorrer que ao facer o balance global, o superávit monetario obtido cos produtos excedentarios non chegue a compensar o diñeiro que hai que empregar para mercar produtos deficitarios.

5.2.2. Nas conclusións sobre a comercialización local ou de proximidade hai que ter en conta as limitacións derivadas dos cálculos de consumos e rendementos que xa temos expostas, e que poden levar a unha sobreestimación da capacidade que existe en cada comarca para cubrir as necesidades de consumo da súa poboación. Con esta prevención, podemos dicir que esta capacidade é bastante elevada. Os/as habitantes potencialmente auto-abastecidos/as dentro da súa propia comarca supera o $50 \%$ no caso dos cultivos forraxeiros, prados e pasteiros e tamén no viñedo. A capacidade de auto-abastecemento supera o $60 \%$ no caso concreto das patacas chegando ao $70 \%$ se incluímos os cultivos hortícolas e as leguminosas gran. Isto probablemente está influenciado polo feito de que a produción para autoconsumo está xeneralizada e nalgúns produtos é moi elevada. No 
seu conxunto, esta produción para consumo propio pode chegar a representar ate o $25 \%$ da renda agraria do país se fora avaliada economicamente a prezos ao consumidor/a (Carreira e Carral, 2014) .

5.2.3. Os cereais gran son os cultivos que teñen un déficit mais elevado e en case todas as bacías alimentares necesitarían ocupar unha superficie maior da que actualmente dispoñen. Tamén se precisaría mais superficie dedicada a froiteiras, mais o déficit é moito máis pequeno.

5.2.4. Nas conclusións sobre as bacías alimentares hai que ter en conta tamén que as limitacións derivadas dos cálculos de consumos e rendementos puideran levar a unha sobreestimación da capacidade de autoabastecemento. A análise das bacías alimentares terrestres das aglomeracións urbanas deixa ver un aspecto negativo: a existencia de problemas puntuais nalgúns grupos de cultivos nos que as producións obtidas dentro delas son insuficientes para abastecer ás poboacións que viven nas mesmas. Pola contra esta análise tamén pon de manifesto un aspecto moi positivo: existe suficiente superficie de cultivo, prados e pasteiros para enfrontar estes problemas pois os balances entre a superficie dispoñíbel actualmente e a superficie necesaria é globalmente positiva en todas as bacías alimentares terrestres.

\section{REFLEXIÓNS FINAIS}

Como complemento aos resultados xa explicados anteriormente, reflexionase a continuación sobre distintas perspectivas que poidan aportar solucións aos problemas detectados.

No caso de que se optara por cubrir o máximo posíbel das necesidades de consumo internas mediante a comercialización local ou de proximidade, creemos que sería posíbel encontrar algunhas alternativas para resolver os problemas puntuais atopados. Unha delas podería ser un cambio de usos da terra dentro da propia comarca ou bacía alimentar. Habería que destinar mais superficie a aqueles cultivos que a precisan para cubrir as necesidades de auto-abastecemento a costa da superficie dedicada a aproveitamentos con producións que superan estas necesidades e que, ademais, teñan parecidas esixencias agronómicas e de solos, algo que semella perfectamente viábel a partir dos dados expostos. Esta estratexia de mudanza de usos da terra tamén permitiría ir cara un deseño de ocupación espacial do territorio máis sustentábel baixo o concepto de "degradación neutral do territorio".

Outra alternativa podería ser aumentar a superficie das bacías alimentares con novas comarcas, algo que non racharía co concepto de comercialización local xa que estivemos a estudar bacías alimentares que admiten algunhas ampliacións, pois estarían dentro do rango das pequenas si as comparamos coas estudadas noutros países.

A esta situación que acabamos de describir non se chegou ao noso entender a partir dunha planificación consciente que englobara a todos os sectores implicados, senón como 
resultado de procesos e dinámicas propias, mesmo autónomas, de cada unha das diferentes tipoloxías de explotacións e dos diferentes territorios agrarios existentes na Galiza. Mais chegados a este punto semella que pode ser unha boa liña de partida no caso de que as instancias políticas e económicas fixaran o obxectivo de aproximarse á soberanía alimentar e/ou ao máximo abastecemento a traveso da comercialización local.

Dado a amplitude das demandas e propostas neste senso, así como a cantidade de adeptos/as que están conseguindo, non sería descartábel que estes obxectivos se chegaran a converter en dous dos mais importantes para a agricultura mundial neste comezo do século XXI. Por iso, e dende o noso punto de vista, o debate sobre a soberanía alimentar e o comercio de proximidade é imprescindíbel tanto dende unha perspectiva xeral como dende a perspectiva concreta da Galiza. Mais non era o obxectivo deste traballo, porque este é un debate cunha importante parte ideolóxica e/ou ademais un debate sobre cales deberían ser os obxectivos político-económicos que as institucións correspondentes terían que fixar para a actividade agraria e para o medio rural tanto no presente coma no futuro. Pola nosa banda o que pretendemos foi achegar algúns dados, ate onde é posíbel e coa obxectividade que nos permiten as nosas posicións previas ao respecto, que tampouco queremos ocultar. A nosa intención é que sirvan de axuda nese debate, no cal e en todo caso nos manifestamos dispostos a participar. 


\section{BIBLIOGRAFÍA}

Alier, J. M., Jusmet, J. R. (2013). Economía ecológica y política ambiental. Fondo de Cultura económica. Fondo de cultura económica. México. ISBN: 9786071615206.

Allen, A. (2003). La interfase periurbana como escenario de cambio y acción hacia la sustentabilidad del desarrollo. Cuadernos del Cendes, 20(53), 7-21. //www.scielo. org.ve/scielo.php?script=sci_arttext\&pid=S1012-25082003000200002\&lng=es\&tl $\mathrm{ng}=\mathrm{en}$.

Altieri, M.A. (2008). Movilizándonos para rescatar nuestro sistema alimentario. CADTM- 2008. http://www.cadtm.org/Movilizandonos-para-rescatar.

Barriuso Rodrigo, A. (2016). Salud y las dietas hiperprotéicas.Trabajo Fin de Grado. Unv. de Valladolid. F. de Enfermería de Soria.

Baysse-Lainé,A. and Perrin,C. (2017). Les espaces agricoles des circuits de proximité : une lecture critique de la relocalisation de l'approvisionnement alimentaire de Millau. Sciences Sociétés 25, 1, 21-35 .DOI: 10.1051/nss/2017.

Born, B., \&Purcell, M. (2006). Avoiding the local trap: Scale and food systems inplanning research. Journal of planning education and research, 26(2), 195-207.

Carreira Pérez, X.C. e Carral Vilariño, E. (2014). "O pequeno é grande. A agricultura familiar como alternativa: O caso galego". Santiago: Através Editora / AGAL.

Ministerio de Medio Ambiente y Medio Rural y Marino.(2010). "Real Decreto 1131/2010, de 10 de septiembre, por el que se establecen los criterios para el establecimiento de las zonas remotas a efectos de eliminación de ciertos subproductos animales no destinados a consumo humano generados en las explotaciones ganaderas". http:// www.boe.es/boe/dias/2010/10/02/pdfs/BOE-A-2010-15123.pdf.

Consellería Medio Rural. Xunta de Galicia. (1999). http://mediorural.xunta.gal/fileadmin/arquivos/estatisticas/macro_1999/C03G.

Consumo responsable.org. "Criterios para un consumo responsable". http://www.consumoresponsable.org/criterios/index. Consultada en decembro 2017.

Corbelle Rico, E. e Crecente Maseda, R. (2008). Estudio da evolución da superficie agrícola na comarca da Terra Chá a partir de fotografía aérea histórica e mapas de usos, 1956-2004. Recursos Rurais. 1,4: pp. 57-65.

Cowie, A.L., Barron J. Orrb, B.J., Castillo-Sanchez, V.M., Chasek, P, Crossman, N.D., Erlewein, A., Louwagie,G., Maron, M., Metternicht, G.I., Minelli, S., Tengberg, A.E., Walter, S., Welton, S. (2018). Land in balance: The scientific conceptual framework for Land Degradation Neutrality. Environmental Science \& Policy, 19. pp 25-23. https://doi.org/10.1016/j.envsci.2017.10.011.

da Silva, L.B. (2016). Impacto econômico e soberania alimentar e nutricional: um estudo de caso na comunidade negra rural Palenqueira San Juan de Palos Prieto, região do Caribe Colombiano. Revista Nera-ANO 19, No. 32 - Dossiê 2016 - ISSN: 18066755. pp. 195-213.

De Schutter, O. (2010). "Informe del Relator Especial sobre el derecho a la alimentación, Sr. Olivier De Schutter" Consejo de Derechos Humanos- Naciones Unidas. 
http://www.srfood.org/images/stories/pdf/officialreports/20110308_a-hrc-16-49_ agroecology_es.pdf.

Diouf, J. (2002). Prefacio de Agricultura mundial: hacia los años 2015/2030. Informe resumido ISBN 92-5-304761-5.

Delgado Manuel, D. (2017). Reestructuración del sistema agroalimentario globalizado en el capitalismo terminal. PAPELES de relaciones ecosociales y cambio global, 139, pp. 13-25.

DeLind, L. B. (2011). Are local food and the local food movement taking us where we want to go? Or are wehitching our wagons to the wrong stars? Agriculture and human values, 28(2), 273-283.

Diouf, J. (2002). Prefacio de Agricultura mundial: hacia los años 2015/2030. Informe resumido.ISBN 92-5-304761-5.

Du Puis, E. M., Goodman, D. (2005). Should we go "home" to eat?: toward a reflexive politics of localism. Journal of rural studies, 21(3), 359-371.

FAO (2012). Pérdidas y desperdicios de alimentos en el mundo. Alcance, causas y prevención, Roma.

FAO (2009). "Como alimentar al mundo en 2050”. En http://www.fao.org/fileadmin/templates/wsfs/docs/synthesis_papers/C\%C3\%B3mo_alimentar_al_mundo_en_2050. pdf.

FAO, IFAD, WFP (2015). The state of food in security in the world 2015. Meeting the 2015 international hunger targets: taking stock of uneven progress. Rome, Italy: FAO.

Galzki, J.C., Mulla, D.J., Peters, C.J. (2014). Mapping the potential of local food capacity in Southeastern Minnesota. Renewable Agriculture and Food Systems, 30(4); 364-372 doi:10.1017/S1742170514000039.

Garcia Lozano, J. (2017). "Santiago é o terceiro concello galego en consumo de produtos ecolóxicos". La Voz de Galicia (2017). https://www.lavozdegalicia.es/noticia/ santiago/santiago/2017/05/18/secretario-consello-regulador-agricultura-ecoloxicagalicia-craegaspan-langglsantiago-e-terceiro-concello-galego-consumo-produtosecoloxicos-spancraega-compostela/0003_201705S18C12991.htm

Hanspach, J., Abson, D.J., Collier, N.F., Dorresteijn, I., Schultner, J., Fischer, J. (2017). From trade-offs to synergies in food security and biodiversity conservation. Front Ecol Environ,15(9):489-494,doi:10.1002/fee.1632.

Instituto Nacional de Estadística (INE).2009. “Censo Agrarioo 2009. Metodología”. http://www.ine.es/daco/daco42/agricultura/meto_censoag09.pdf.

Kloppenburg, J., Hendrickson, J., Stevenson, G. W. (1996). Coming in to the foodshed. Agriculture and human values, 13(3), 33-42.

Kust, G., Andreeva O., Cowie, A. (2017). Land Degradation Neutrality: Concept development, practical applications and assessment. Journal of Environmental Management, 195, 16-24.http://dx.doi.org/10.1016/j.jenvman.2016.10.043.

Lang, T. (2006). Food Miles. Slow Food (Bra, Cuneo, Italy) 94-97. 
López García, D. (2011). Canales cortos de comercialización como elemento dinamizador de las agriculturas ecológicas urbana y periurbana. I Congreso Estatal de Agricultura Ecológica Urbana y Periurbana. Elx, Alicante. 6 y 7 de mayo 2011.

McIntyre, B. D. (2009). International assessment of agricultural knowledge, science and technology for development. (IAASTD): global report.

Ministerio de Agricultura y Pesca y Alimentación y Medio Ambiente (2017). "El Ministerio de Agricultura y Pesca, Alimentación y Medio Ambiente promociona el consumo de frutas de temporada". http://www.mapama.gob.es/es/prensa/noticias/el-ministerio-de-agricultura-y-pesca-alimentación-y-medio-ambiente-promocionael-consumo-de-frutas-de-temporada/tcm7-460756-16.

Ministerio de Medio Ambiente y Medio Rural y Marino. 2010. "Real Decreto 1131/2010, de 10 de septiembre, por el que se establecen los criterios para el establecimiento de las zonas remotas a efectos de eliminación de ciertos subproductos animales no destinados a consumo humano generados en las explotaciones ganaderas". http:// www.boe.es/boe/dias/2010/10/02/pdfs/BOE-A-2010-15123.pdf.

Naredo, J.M. (2015). La economía en evolución. Historias y perspectivas de las categorías básicas del pensamiento económico. Siglo XXI. Madrid.

Pena, S. (2010). La castaña gallega busca un sitio en la mesa. http://www.elmundo.es/ elmundo/2010/10/10/galicia/1286730560.html.

Pérez-Neira, D., Grollmus-Venegas, A. (2018). Life-cycle energy assessment and carbon footprint of peri-urbanhorticulture. A comparative case study of local food systems in Spain. Landscape and Urban Planning. https://doi.org/10.1016/j.landurbplan.2018.01.001.

Perfecto, I., Vandermeer, J. (2012). Separación o integración para la conservación de biodiversidad: la ideología detrás del debate" land-sharing" frente a" land-sparing". Revista Ecosistemas, 21(1-2).

Subdirección General de Estructura de la Cadena Alimentaria. Dirección General de la Industria Alimentaria. Ministerio de Agricultura y Pesca y Alimentación y Medio Ambiente (2017). "Base de Datos de Consumo en Hogares". http://www.mapama. gob.es/es/alimentacion/temas/consumo-y-comercializacion-y-distribucion-alimentaria/panel-de-consumo-alimentario/base-de-datos-de-consumo-en-hogares/consulta.asp.

Tello, E., Garrabou, R., Cussó, X., Olarieta, J.R. (2008). Una interpretación de los cambios de uso del suelo desde el punto de vista del metabolismo social agrario. La comarca catalana del Vallès, 1853-2004. Revista Iberoamericana de Economía Ecológica, 7: 97-115.

Tilman D., Balzer C., Hill J., BefortBL. (2011). Global food demand and the sustainablei ntensification of agriculture. P Nat Acad Sci USA, 108: 20, 260-64.

UN (2015). Transforming our world: the 2030 Agenda for Sustainable Development. United Nations, The General Assembly. http://bit.ly/1OTd4Sr. 
Via Campesina. (2003). “Qué es la soberanía alimentaria”. https://viacampesina.org/es/ que-es-la-soberania-alimentaria/.

Watkiss, P., Schmith, A., Tweddle, G., \&McKinnon, A. (2005). "The validity of food miles as an indicator of sustainable development". http://www.intracen.org/uploadedFiles/intracenorg/Content/Exporters/Sectors/Fair_trade_and_environmental_exports/Climate_change/validity\%20of\%20food\%20miles.pdf.

Weber, C. L., Matthews, H. S. (2008). Food-miles and the relative climate impacts of food choices in the United States. Environ Sci Technol. 42(10): 3508-13.

Winograd, M. (2012). "Promoción del consumo de productos generados en la horticultura periurbana”. En: Mitidieri, M.; Corbino, G.; eds. Manual de horticultura periurbana.

WWF (2017). Appetite For Destruction. Summary_Report_Sign Off. http://www .wwf. org.uk.

Yacamán, C., Mata Olmo, R. (2014). La gobernanza territorial y alimentaria como base para la protección y dinamización del espacio agrario periurbano. Estudio de caso del parque agrario de Fuenlabrada (comunidad de Madrid). XVII Coloquio de Geografía Rural, 275-288.

Ziegler, J. (2007). UN News Centre ( 2007). "UN independent rights experts call for five-year freeze on biofuel production". http://www.un.org/apps/news/story. asp?NewsID=24434\&\#.WhbFxrpFycy.

Zumkehr, A., Campbell, J.E. (2015). "The potential for local croplands to meet US food demand". Frontiers in Ecology and the Environment, 13(5): 244-248. 